\title{
Why government bonds are sold by auction and corporate bonds by posted-price selling
}

\author{
Ziegler, Alexandre ; Habib, Michel A
}

\begin{abstract}
When information is costly, a seller may wish to prevent prospective buyers from acquiring information, for the cost of information acquisition ultimately is borne by the seller. A seller can achieve the desired prevention through posted-priceselling, by offering prospective buyers a discount. No such prevention is possible in the case of an auction. We establish the result that the seller prefers posted-priceselling when the cost of information acquisition is high andauctions when it is low. We view corporatebonds as an instance of the former case, andgovernmentbonds as an instance of the latter.
\end{abstract}

DOI: https://doi.org/10.1016/j.jfi.2007.03.006

Posted at the Zurich Open Repository and Archive, University of Zurich

ZORA URL: https://doi.org/10.5167/uzh-63187

Journal Article

Accepted Version

Originally published at:

Ziegler, Alexandre; Habib, Michel A (2007). Why government bonds are sold by auction and corporate bonds by posted-price selling. Journal of Financial Intermediation, 16(3):343-367.

DOI: https://doi.org/10.1016/j.jfi.2007.03.006 


\title{
WHY GOVERNMENT BONDS ARE SOLD BY AUCTION AND CORPORATE BONDS BY POSTED-PRICE SELLING
}

\author{
Michel Habib* Alexandre Ziegler ${ }^{\dagger}$
}

January 31, 2003

Version: $1^{\ddagger}$

\begin{abstract}
When information is costly, a seller may wish to prevent prospective buyers from acquiring information, for the cost of information acquisition is ultimately borne by the seller. A seller can achieve the desired prevention of information acquisition through posted-price selling, by offering prospective buyers a discount that is such as to deter them from gathering information. No such prevention is possible in the case of an auction. Clearly, a discount is costly to the seller. We establish the result that the seller prefers posted-price selling when the cost of information acquisition is high, and auctions when it is low. We view corporate bonds as an instance of the former case, and government bonds as an instance of the latter.
\end{abstract}

JEL Nos.: D44, G30.

Keywords: Government Bonds, Corporate Bonds, Auctions, Posted-Price Selling, Costly Information.

${ }^{*}$ Swiss Banking Institute, University of Zurich, Plattenstrasse 14, 8032 Zurich, Switzerland; tel.: +41-(0)1-6342507; e-mail: habib@isb.unizh.ch.

${ }^{\dagger}$ Ecole des HEC, University of Lausanne and FAME, BFSH 1, 1015 Lausanne-Dorigny, Switzerland; tel.: +41(0)21-692-3351; e-mail: aziegler@hec.unil.ch.

${ }^{\ddagger}$ We thank Rajna Gibson, Christine Hirszowicz and Avi Wohl for valuable comments. Habib would like to thank the NCCR for financial support. The usual disclaimer applies. 


\section{WHY GOVERNMENT BONDS ARE SOLD BY AUCTION AND CORPORATE BONDS BY POSTED-PRICE SELLING}

\section{Introduction}

In most industrialized countries, government bonds are sold by auction whereas corporate bonds are sold by posted-price selling (PPS). The latter form of sale, which is described by Grinblatt and Titman (1998, p. 58) for example, effectively has the investment bank bringing the issue to market set the price at which the securities are offered, albeit in consultation with the issuer and prospective buyers. This is in contrast to auctions, in which the sale price of the securities offered for sale is obtained from the bids made by the participants in the auction. In the uniform-price auction used by the Treasury to sell two-year and five-year notes, for example, the winning bidders pay the highest losing bid. ${ }^{1}$

Our purpose in this paper is to provide an explanation for the afore-mentioned empirical regularity. The starting point of our analysis are the observations that i) information about a security such as a bond is costly to acquire, ii) investors have an incentive to acquire information, and iii) the cost of the information acquired by investors is ultimately borne by the seller of the security. An investor who acquires information gains an informational advantage over both the seller and those investors who have not acquired information, and can expect to profit at their expense. Foreseeing the losses they will incur to informed investors, uninformed investors shade their bids in case the security is auctioned, or require from the seller a discount to the expected value of the security in case the security is sold by PPS. ${ }^{2}$ Uninformed investors may even withdraw from the sale, thereby decreasing competition for the security and the seller's expected proceeds from the sale.

The reduction in the seller's expected proceeds caused by information acquisition by investors suggests that the seller would like to prevent such acquisition. This can be achieved by having the seller post a price that offers investors a discount to the expected value of the security. The discount is such that investors are indifferent between i) incurring the cost of acquiring information and exploiting the informational advantage thereby obtained, and ii) refraining from acquiring information, taking part in the sale, and obtaining the discount.

In contrast, no such prevention is possible in the case of an auction. This is because the sale price in an auction is set not by the investment bank bringing the security to market, but by the bids submitted. Under such conditions, the expected payoff of an uninformed bidder is at most zero (Milgrom and Weber, 1982b), and only those investors who have acquired information will place

\footnotetext{
${ }^{1}$ See Bikchandani and Huang (1993) for an analysis of the Treasury securities markets.

${ }^{2}$ See Milgrom and Weber (1982a) for auctions and Rock (1987) for PPS.
} 
bids in an auction. Under conditions of free entry into the auction, a bidder's expected payoff from placing a bid therefore equals the cost of acquiring information. As the seller's payoff equals the expected value of the security minus the bidders' expected payoffs, the seller's expected proceeds equal the expected value of the security minus the combined cost of information acquisition. ${ }^{3}$

Of course, the discount granted the buyer under PPS is costly to the seller but, under some conditions, it is less costly than the alternative of having the investor acquire information in an auction. We shall show the underpricing in an auction to be higher than the discount offered under PPS when the cost of information acquisition is high, and lower when this cost is low.

Intuitively, a high discount must be offered under PPS in order to prevent investors from acquiring information when the cost of information acquisition is low. In the limit, when information is costless, only a price equal to the lower bound on the value of the security can deter investors from acquiring information under PPS. In contrast, costless information reduces the auction to one with no entry costs. Should a sufficiently large number of investors then enter the auction, the price should converge to the expected value of the security (Wilson, 1977; Milgrom, 1981).

When the cost of information acquisition is relatively high, little or no discount to the expected value of the security must be offered investors in order to deter them from acquiring information. In contrast, the high cost of information acquisition - which is borne by the seller in expectation - decreases expected seller proceeds from the auction below the expected value of the security.

How can the preceding reasoning explain the differing choice of selling mechanism for government and corporate bonds? Industrialized country government bonds are for the most part free of default risk, whereas corporate bonds are not. This suggests that the cost of information acquisition is lower for government bonds than it is for corporate bonds. It is consistent with the choice of auctions for the former and PPS for the latter.

Previous comparisons of auctions and PPS can be found in both economics and finance. The economics literature has mainly considered the case of private values. ${ }^{4}$ We believe the assumption of common value values to be more appropriate for our analysis of financial securities such as bonds that are traded in secondary markets. ${ }^{5}$ The finance literature has compared common value auctions and book-building, itself a form of PPS (Spatt and Srivastava, 1991), in the context of initial public offerings (IPOs). ${ }^{6}$ We note at this point that our explanation recalls that offered by Sherman (2001) to explain the prevalence of book-building in IPOs: PPS affords the seller better control over the amount of information acquired by investors. We return to IPOs in Section $6 .{ }^{7}$

\footnotetext{
${ }^{3}$ This result is due to French and McCormick (1984). See also Harstad (1990) and Levin and Smith (1994).

${ }^{4}$ See for example Wang (1993) and Arnold and Lippman (1995).

${ }^{5}$ Wang (1998) analyses the intermediate case of correlated private values.

${ }^{6}$ See Chemmanur and Liu (2001) and Sherman (2001).

${ }^{7}$ Madhavan (1992) compares auction and dealer markets. We believe his analysis of secondary markets not to be entirely applicable to the the primary markets that we consider. This is because previous trading in a security makes
} 
We proceed as follows. In Section 2, we consider the case of second-price auctions. In Section 3, we consider that of PPS. We compare auctions and PPS in Section 4. Section 5 illustrates our results by means of an example. We briefly examine the implications of our analysis for IPOs in Section 6. We conclude in Section 7.

\section{Second-price auctions}

The first part of the present section is based on French and McCormick (1984). It is included in order to introduce the notation and for completeness.

Consider a seller who wishes to sell a security that has unknown value $V$. This value has cumulative distribution function $F_{V}($.$) and probability density function f_{V}($.$) over the interval$ $\left[V_{l}, V_{h}\right]$.

There are $N>1$ investors, indexed by $i=1, \ldots, N$. Investor $i$ can, if he so desires, acquire information $X_{i}$ at a cost $c$ about the value of the security before entering his bid. We consider a pure common value model, $X_{i}=V+\varepsilon_{i}$, with the error term $\varepsilon_{i}$ independent of $V$ and i.i.d. across $i$.

We let $n^{*}, 0 \leq n^{*} \leq N$, denote the number of investors who choose to incur the cost of acquiring information. The number $n^{*}$ is also the number of bidders in the auction, because any bidder who has not acquired information has an expected payoff that is at most equal to zero (Milgrom and Weber, 1982b). Once all $n^{*}$ bids have been entered, the security is sold to the highest bidder, at a price equal to the second highest bid. ${ }^{8}$

By virtue of the symmetry across investors and bidders, we limit our analysis to bidder $1 .{ }^{9} \mathrm{We}$ drop the subscript 1 for ease of notation: $X \equiv X_{1}$. We let $Y_{n^{*}-1}$ denote the highest order statistic of the signals $X_{2}, \ldots, X_{n^{*}}$ received by the remaining $n^{*}-1$ bidders.

Following Milgrom and Weber (1982b), we define $v_{n^{*}-1}(x, y) \equiv E\left[V \mid X=x, Y_{n^{*}-1}=y\right]$. Bidder 1 forms the expectation $v_{n^{*}-1}(x, y)$ of the value of the security on receiving the information

the cost of acquiring information about the security - a central component of our analysis - much lower for secondary markets than for primary markets.

${ }^{8}$ The assumption of second-price auction is without loss of generality for the general results of Sections 2,3 , and 4. It is made because i) it corresponds to the uniform-price auctions used to sell government bonds and ii) it permits the use of the closed-form solution for bidder profits computed by Kagel, Levin and Harstad's (1995) in the example of Section 5.

${ }^{9}$ Milgrom (1981) shows the existence of a symmetric pure strategy equilibrium. Harstad (1991) shows that the symmetric equilibrium is the only locally nondegenerate risk neutral Nash equilibrium in increasing bid strategies if there are more than 3 bidders. (An equilibrium is locally nondegenerate when the probability of any given bidder winning the auction is positive for all bidders.) See also Kagel et al. (1995). 
$X=x$ and on presuming the highest order statistic amongst the remaining signals is $Y_{n^{*}-1}=y$.

We know from Milgrom and Weber (1982b) that bidder 1 bids $^{10}$

$$
v_{n^{*}-1}(x, x)=E\left[V \mid X=x, Y_{n^{*}-1}=x\right] .
$$

Intuitively, bidder 1 adjusts his estimate of the value of the security for the fact that he wins the auction when he receives the highest signal amongst the $n^{*}$ signals $X_{1}, \ldots, X_{n^{*}}$. His presumption that the second highest signal is equal to the highest signal - which he has received - ensures that he does not lose the auction to a bidder who has received a lower signal than he has. Bidder 1 is induced to bid truthfully because the second price auction implies that his bid affects his probability of winning the auction but not the price he pays upon winning.

Symmetry across bidders implies that the seller's expected proceeds equal

$$
\Pi_{n^{*}}=E\left[v_{n^{*}-1}\left(Y_{n^{*}-1}, Y_{n^{*}-1}\right) \mid X>Y_{n^{*}-1}\right]
$$

and that a bidder's expected profit - gross of the cost of acquiring information - equals

$$
\pi_{n^{*}}=\frac{1}{n^{*}}\left(E[V]-E\left[v_{n^{*}-1}\left(Y_{n^{*}-1}, Y_{n^{*}-1}\right) \mid X>Y_{n^{*}-1}\right]\right) .
$$

Free entry in turn implies that $n^{*}$ is such that $\pi_{n^{*}}=c$. Combining, we can rewrite the seller's expected proceeds as $\Pi_{n^{*}}=E[V]-n^{*} c$. As noted in the introduction, the combined cost of information acquisition is borne by the seller and determines the extent of underpricing. This result was first derived by French and McCormick (1984).

We now wish to examine the comparative statics of $\Pi_{n^{*}}$ with respect to the cost of acquiring information $c$, the quality of the information that can be obtained about the value of the security, and the riskiness of the security. For that purpose, we must first determine the variation of a bidder's expected profit as a function of the number of bidders, $\partial \pi_{n^{*}} / \partial n^{*}$.

There is no general result concerning

$$
\frac{\partial \pi_{n^{*}}}{\partial n^{*}}=-\frac{\pi_{n^{*}}}{n^{*}}-\frac{1}{n^{*}} \frac{\partial E\left[v_{n^{*}-1}\left(Y_{n^{*}-1}, Y_{n^{*}-1}\right) \mid X>Y_{n^{*}-1}\right]}{\partial n^{*}} .
$$

This is because $\partial E\left[v_{n^{*}-1}\left(Y_{n^{*}-1}, Y_{n^{*}-1}\right) \mid X>Y_{n^{*}-1}\right] / \partial n^{*}$ cannot be signed. On the one hand, a larger number of bidders increases $Y_{n^{*}-1}$, the maximum of the signals received by the now larger number of bidders other than bidder 1. A higher signal $Y_{n^{*}-1}$ implies a higher estimate of the value of the security, $v_{n^{*}-1}\left(Y_{n^{*}-1}, Y_{n^{*}-1}\right)$. On the other hand, a larger number of bidders decreases the estimate of the value of the security $v_{n^{*}-1}\left(Y_{n^{*}-1}, Y_{n^{*}-1}\right)$ for a given signal $Y_{n^{*}-1}$. This is because

\footnotetext{
${ }^{10}$ Levin and Harstad (1986) show that this function is the unique symmetric Nash equilibrium.
} 
a larger number of bidders necessitates a greater downward adjustment for the winner's curse on the part of the winner of the auction.

Milgrom (1981) has shown that $\partial E\left[v_{n^{*}-1}\left(Y_{n^{*}-1}, Y_{n^{*}-1}\right) \mid X>Y_{n^{*}-1}\right] / \partial n^{*}>0$ as $n^{*}$ becomes large. We assume in what follows that the preceding inequality holds true over the range of $n^{*}$ that we shall encounter.

We represent a decrease in the quality of the information by a garbling $\Xi$ of the information $X_{i}$, with $E[\Xi \mid V]=E\left[\Xi \mid \varepsilon_{i}\right]=0$. The information available to a bidder who has incurred the cost $c$ is now $X_{i}^{\prime} \equiv X_{i}+\Xi$. The corresponding highest order statistic is $Y_{n^{*}-1}^{\prime}=Y_{n^{*}-1}+\Xi$. We note that the garbling $\Xi$ is identical across bidders. It can be viewed as some bidder-wide decrease in the informativeness of the signals that investors can acquire.

The nature of $X^{\prime}$ as a garbling of $X$ and of $Y_{n^{*}-1}^{\prime}$ as a garbling of $Y_{n^{*}-1}$ implies that

$$
\begin{aligned}
w_{n^{*}-1}\left(x, y, x^{\prime}, y^{\prime}\right) & \equiv E\left[V \mid X=x, Y_{n^{*}-1}=y, X^{\prime}=x^{\prime}, Y_{n^{*}-1}^{\prime}=y^{\prime}\right] \\
& =E\left[V \mid X=x, Y_{n^{*}-1}=y\right] \\
& =v_{n^{*}-1}(x, y) .
\end{aligned}
$$

We can now use the well known result that expected proceeds increase in the information available to bidders (Milgrom and Weber, 1982b) to write

$$
\begin{aligned}
E\left[v_{n^{*}-1}\left(Y_{n^{*}-1}, Y_{n^{*}-1}\right) \mid X>Y_{n^{*}-1}\right] & =E\left[w_{n^{*}-1}\left(Y_{n^{*}-1}, Y_{n^{*}-1}, Y_{n^{*}-1}^{\prime}, Y_{n^{*}-1}^{\prime}\right) \mid X>Y_{n^{*}-1}\right] \\
& =E\left[w_{n^{*}-1}\left(Y_{n^{*}-1}, Y_{n^{*}-1}, Y_{n^{*}-1}^{\prime}, Y_{n^{*}-1}^{\prime}\right) \mid X^{\prime}>Y_{n^{*}-1}^{\prime}\right] \\
& \geq E\left[v_{n^{*}-1}\left(Y_{n^{*}-1}^{\prime}, Y_{n^{*}-1}^{\prime}\right) \mid X^{\prime}>Y_{n^{*}-1}^{\prime}\right] .
\end{aligned}
$$

The first equality is obtained by equation (5), the second by noting that

$$
X^{\prime}>Y_{n^{*}-1}^{\prime} \Longleftrightarrow X+\Xi>Y_{n^{*}-1}+\Xi \Longleftrightarrow X>Y_{n^{*}-1}
$$

and the third by the result that expected proceeds increase in the information available to bidders. The lower expected seller proceeds for a given number of bidders $n^{*}$ imply a higher profit per bidder, and induce a higher number of bidders $n^{* \prime}$ to enter the auction. We therefore have $n^{* \prime}>n^{*}$ and $\Pi_{n^{* \prime}}=E[V]-n^{* \prime} c<\Pi_{n^{*}}$. Thus, the lower the quality of the information that can be obtained about the value of the security, the larger the number of bidders participating in the auction and the lower the seller's expected proceeds.

We now consider the change in expected proceeds that results from a change in the riskiness of the security. We represent an increase in riskiness by a mean-preserving spread $\Psi$ applied to the value $V$ of the security, with $E[\Psi \mid V]=0$. We define $V^{\prime \prime} \equiv V+\Psi$ and have corresponding signal $X_{i}^{\prime \prime}=V^{\prime \prime}+\varepsilon_{i}=X_{i}+\Psi$ and highest order statistic $Y_{n^{*}-1}^{\prime \prime}=Y_{n^{*}-1}+\Psi$. 
We first note that

$$
\begin{aligned}
v_{n^{*}-1}(x, y) & =E\left[V \mid X=x, Y_{n^{*}-1}=y\right] \\
& =E\left[V \mid X^{\prime \prime}=x+\psi, Y_{n^{*}-1}^{\prime \prime}=y+\psi, \Psi=\psi\right] \\
& =E\left[V^{\prime \prime}-\Psi \mid X^{\prime \prime}=x+\psi, Y_{n^{*}-1}^{\prime \prime}=y+\psi, \Psi=\psi\right] \\
& =E\left[V^{\prime \prime} \mid X^{\prime \prime}=x+\psi, Y_{n^{*}-1}^{\prime \prime}=y+\psi, \Psi=\psi\right]-\psi \\
& \equiv w_{n^{*}-1}(x+\psi, y+\psi, \psi)-\psi .
\end{aligned}
$$

We can now write

$$
\begin{aligned}
E\left[v_{n^{*}-1}\left(Y_{n^{*}-1}, Y_{n^{*}-1}\right) \mid X>Y_{n^{*}-1}\right]= & E\left[w_{n^{*}-1}\left(Y_{n^{*}-1}+\Psi, Y_{n^{*}-1}+\Psi, \Psi\right)-\Psi \mid X>Y_{n^{*}-1}\right] \\
= & E\left[w_{n^{*}-1}\left(Y_{n^{*}-1}+\Psi, Y_{n^{*}-1}+\Psi, \Psi\right)-\Psi \mid X+\Psi>Y_{n^{*}-1}+\Psi\right] \\
= & E\left[w_{n^{*}-1}\left(Y_{n^{*}-1}^{\prime \prime}, Y_{n^{*}-1}^{\prime \prime}, \Psi\right)-\Psi \mid X^{\prime \prime}>Y_{n^{*}-1}^{\prime \prime}\right] \\
= & E\left[w_{n^{*}-1}\left(Y_{n^{*}-1}^{\prime \prime}, Y_{n^{*}-1}^{\prime \prime}, \Psi\right) \mid X^{\prime \prime}>Y_{n^{*}-1}^{\prime \prime}\right] \\
& -E\left[\Psi \mid X^{\prime \prime}>Y_{n^{*}-1}^{\prime \prime}\right] \\
= & E\left[w_{n^{*}-1}\left(Y_{n^{*}-1}^{\prime \prime}, Y_{n^{*}-1}^{\prime \prime}, \Psi\right) \mid X^{\prime \prime}>Y_{n^{*}-1}^{\prime \prime}\right] \\
& -E\left[E[\Psi \mid V] \mid X^{\prime \prime}>Y_{n^{*}-1}^{\prime \prime}\right] \\
\geq & E\left[v_{n^{*}-1}^{\prime \prime}\left(Y_{n^{*}-1}^{\prime \prime}, Y_{n^{*}-1}^{\prime \prime}\right) \mid X^{\prime \prime}>Y_{n^{*}-1}^{\prime \prime}\right] .
\end{aligned}
$$

where $v_{n^{*}-1}^{\prime \prime}\left(x^{\prime \prime}, y^{\prime \prime}\right) \equiv E\left[V^{\prime \prime} \mid X^{\prime \prime}=x^{\prime \prime}, Y_{n^{*}-1}^{\prime \prime}=y^{\prime \prime}\right]$. Inequality (8) is established in a manner similar to that used to establish inequality (6), using the result that expected proceeds increase in the information available to bidders. As for the case of a decrease in the quality of the information, an increase in the riskiness of the security increases the number of bidders entering the auction from $n^{*}$ to $n^{* \prime \prime}$ and decreases expected seller proceeds to $\Pi_{n^{* \prime \prime}}=E[V]-n^{* \prime \prime} c{ }^{11}$

We now consider the change in expected seller proceeds that results from an increase in the cost of acquiring information, $c$. Clearly, an increase in $c$ decreases the number of bidders. Whether the product $n^{*} c$ increases or decreases in $c$ depends on the elasticity of $n^{*}$ with respect to $c$. Expected seller proceeds decrease in $c$ when the elasticity is greater than 1 , and increase when it is less than 1.

To summarize, the seller's proceeds from the auction increase with the quality of the information available to bidders, decrease with the riskiness of the security, and depend ambiguously on the information acquisition cost, $c$.

\footnotetext{
${ }^{11}$ That expected proceeds increase in the information available to bidders is central to the derivation of inequalities (6) and (8) above. The intuition is that the higher the quality of the information available to bidders, the more similar bidders' assessement of the value of the security, the closer therefore the second highest bid to the highest bid and the higher expected proceeds. The two derivations differ in that the effect of information quality is direct in (6) whereas it is indirect in (8). In the latter case, the greater volatility makes the value of the security more difficult to estimate. This difference explains why the derivation of (8) is somewhat more involved than that of (6).
} 


\section{Posted-price selling}

We now consider the case where the seller sells the security using PPS. We consider only postedprice schemes that deter investors from acquiring information. This is because posted-price schemes that fail to deter investors from acquiring information are likely to be dominated by auctions. ${ }^{12}$

How can the seller preclude the acquisition of information? The solution is to post a price $P<E[V]$ that is such as to leave each of the $N$ investors indifferent between i) incurring the cost of acquiring information and exploiting the informational advantage thereby obtained, and ii) refraining from acquiring information, taking part in the sale, and obtaining the discount $E[V]-P$ if allocated the security. Formally, $P$ is such that

$$
\frac{E\left[\max \left[E\left[V \mid X_{i}\right]-P, 0\right]\right]}{N}-c=\frac{E[V]-P}{N} .
$$

Rewriting,

$$
\begin{aligned}
c & =\frac{E\left[\max \left[E\left[V \mid X_{i}\right]-P, 0\right]\right]}{N}-\frac{E\left[E\left[V \mid X_{i}\right]-P\right]}{N} \\
& =\frac{1}{N} E\left[\max \left[P-E\left[V \mid X_{i}\right], 0\right]\right] .
\end{aligned}
$$

Equation (10) indicates that the price $P$ must be such that the expected loss from buying an overvalued security is equal to the cost of acquiring information that would serve to guard against doing so. Note that the expected loss reflects the $1 / N$ probability of being allocated the security when no other potential buyer acquires information.

We first note that (10) implies that $\partial P / \partial c>0$. This is simply a consequence of the fact that a lower discount needs be offered investors to deter them from acquiring more costly information. In the case where information is costless, the acquisition of information can be prevented only by

\footnotetext{
${ }^{12}$ That posted-price schemes that fail to deter investors from acquiring information are likely to be dominated by auctions is suggested by the results of Harstad (1990) and Bulow and Klemperer (1996). Harstad (1990) shows that entry costs are borne by the seller in expectation. (Although he considers only auctions, his results can easily be extended to PPS.) This implies that expected seller proceeds are higher with an auction when the auction induces less entry than does PPS, that is when $n^{*} \leq n^{P P S}$, where $n^{P P S}$ denotes the number of investors who acquire information under PPS. (Note that under PPS with information acquisition as with an auction, investors who do not acquire information do not participate.) When $n^{*}>n^{P P S}$, Bulow and Klemperer (1996) show that expected seller proceeds are higher with an ascending auction with $n^{*}$ bidders than with PPS with $n^{P P S}<n^{*}$ bidders. This is because the greater competition that results from the presence of one or more additional bidders in the auction is more valuable to the seller than the increased bargaining power that comes from the posting of a price, which is equivalent to making a take-it-or-leave-it offer. We note that the results of Bulow and Klemperer (1996) are only suggestive in our case, because we consider a second-price rather than an ascending auction.
} 
setting a price $P=V_{l} .{ }^{13}$ This is because information has value for all prices above $V_{l}$ in such case.

We then consider the effect of a garbling of the information that investors can acquire. As in Section 2, we denote $X_{i}^{\prime}$ the garbled information. We know from Blackwell (1953) and Blackwell and Girshick (1954) that if $X_{i}^{\prime}$ is a garbling of $X_{i}$, then $E\left[V \mid X_{i}\right]$ is a mean-preserving spread of $E\left[V \mid X_{i}^{\prime}\right]$. This is because the higher the quality of the information, the more distinguishable the conditional expectation from the unconditional expectation, and therefore the more diffuse the distribution of the conditional expectation. As the LHS of equation (10) is convex in the conditional expectation and increasing in the price posted, we have $P \leq P^{\prime}$, where $P^{\prime}$ denotes the price that deters investors from acquiring the garbled information $X^{\prime}$. In words, a higher discount must be offered investors to deter them from acquiring higher quality information.

Finally, we consider the effect of a change in the riskiness of the security. As in Section 2, we represent an increase in riskiness by a mean-preserving spread $\Psi$ applied to the value $V$ of the security, with $E[\Psi \mid V]=0$. We have $V^{\prime \prime}=V+\Psi$ and corresponding signal $X_{i}^{\prime \prime}=V^{\prime \prime}+\varepsilon_{i}=X_{i}+\Psi$.

We first note that

$$
E\left[V^{\prime \prime} \mid X_{i}\right]=E\left[V+\Psi \mid X_{i}\right]=E\left[V \mid X_{i}\right]
$$

We then note that $X_{i}^{\prime \prime}=V^{\prime \prime}+\varepsilon_{i}$ constitutes higher quality information about $V^{\prime \prime}$ than does $X_{i}=V^{\prime \prime}-\Psi+\varepsilon_{i} \cdot{ }^{14}$ From Blackwell (1953) and Blackwell and Girshick (1954), this implies that $E\left[V^{\prime \prime} \mid X_{i}^{\prime \prime}\right]$ has a more diffuse distribution than does $E\left[V^{\prime \prime} \mid X_{i}\right]$.

We can now write

$$
\begin{aligned}
E\left[\max \left[P^{\prime \prime}-E\left[V^{\prime \prime} \mid X_{i}^{\prime \prime}\right], 0\right]\right] & =N c \\
& =E\left[\max \left[P-E\left[V \mid X_{i}\right], 0\right]\right] \\
& =E\left[\max \left[P-E\left[V^{\prime \prime} \mid X_{i}\right], 0\right]\right] \\
& \leq E\left[\max \left[P-E\left[V^{\prime \prime} \mid X_{i}^{\prime \prime}\right], 0\right]\right] .
\end{aligned}
$$

where $P^{\prime \prime}$ denotes the price that deters investors from acquiring information when the security has value $V^{\prime \prime}$. Inequality (11) implies that $P^{\prime \prime} \leq P$. In words, a higher discount must be offered investors to deter them from acquiring information about a more risky security.

\footnotetext{
${ }^{13}$ To show this formally, let $z \equiv E\left(V \mid X_{i}\right)$ and denote $H(z)$ the prior distribution of $z$. Condition (10) becomes$$
c=\frac{1}{N} \int_{V_{l}}^{P}(P-z) d H(z)
$$

The seller must set $P=V_{l}$ for this condition to hold when $c=0$.

${ }^{14}$ Note that what may loosely be referred to as the 'signal-to-noise ratio' is larger for $X_{i}^{\prime \prime}$ than it is for $X_{i}$,

$$
\frac{\operatorname{var}\left[V^{\prime \prime}\right]}{\operatorname{var}\left[\varepsilon_{i}\right]}>\frac{\operatorname{var}\left[V^{\prime \prime}\right]}{\operatorname{var}[\Psi]+\operatorname{var}\left[\varepsilon_{i}\right]}
$$


To summarize, the posted price that ensures that no buyer wishes to acquire information - and therefore the seller's revenue - is increasing in the information acquisition cost, and decreasing in the quality of the information available to bidders and in the riskiness of the security.

\section{Auctions and posted-price selling compared}

We are now in a position to compare auctions and PPS. We first consider the effect of the cost of acquiring information, $c$.

As noted in the introduction, auctions can be expected to dominate PPS for small $c$. In the limit, when $c$ is zero, all investors enter the auction. The larger the number of investors $N$, the closer expected seller proceeds are to the expected value of the security $E[V]$ (Milgrom, 1981). In contrast, only a price $P$ equal to lowest value of the security $V_{l}$ can deter investors from acquiring information when information is costless.

We now turn to the case of large $c$. In particular, we consider a cost $c_{h}$ that is such that equation (9) holds even with $P=E[V]$. Formally,

$$
c_{h} \equiv \frac{E\left[\max \left[E\left[V \mid X_{i}\right]-E[V], 0\right]\right]}{N} .
$$

It is clear that no investor has any incentive to acquire information in such case, despite the fact that no discount is offered. This is because the cost of acquiring information is sufficiently high to deter the acquisition of information without the need for a discount. The seller's proceeds therefore equal $E[V]$.

Would expected seller proceeds in an auction also equal $E[V]$ ? We show by contradiction that the answer is in the negative. Suppose the equilibrium is one in which no investor acquires information and all $N$ investors bid $E[V]$ and have expected payoff zero. Consider investor $i$ who contemplates deviating from that equilibrium. His expected payoff from acquiring information at a cost $c_{h}$-and bidding more than $E[V]$ if the information $X_{i}$ he obtains is such that $E\left[V \mid X_{i}\right]>E[V]$ - is $^{15}$

$$
E\left[\max \left[E\left[V \mid X_{i}\right]-E[V], 0\right]\right]-c_{h}=\frac{N-1}{N} E\left[\max \left[E\left[V \mid X_{i}\right]-E[V], 0\right]\right]>0,
$$

Investor $i$ therefore has an incentive to acquire information. This induces some investors other than $i$ to acquire information and other investors to withdraw from the auction. It reduces the auction to the one examined in Section 2, with expected seller proceeds $E[V]-n^{*} c_{h}<E[V] .{ }^{16}$ We therefore conclude that PPS dominates auctions for relatively large $c$.

\footnotetext{
${ }^{15}$ Note that the price paid by bidder $i$ in a second-price auction is $E[V]$, as this is the bid made by the other bidders under the equilibrium considered.

${ }^{16}$ If $c_{h}$ is such that only a single investor enters the auction, expected seller proceeds equal $V_{l}<E[V]$.
} 
Why is the cost $c_{h}$ sufficient to deter information acquisition under PPS but not in an auction? Comparing (12) and (13), we note that what makes the former an equality and the latter an inequality is the factor $1 / N$ in the former. This factor represents the probability of being allocated the security under PPS. Thus, an investor who acquires information that reveals the security to be underpriced $\left(E\left[V \mid X_{i}\right]>E[V]\right)$ is constrained in his ability to profit from this information by the fact that he has only a $1 / N$ probability of being allocated the security under PPS. No such constraint exists in an auction, for the investor can ensure that he receives the security with certainty by bidding more than $E[V]$. In words, the additional degree of freedom conferred investors in an auction - the choice of the bid - and the fact that the security is allocated to the highest bidder increase investors' ability to profit from the information they may acquire and therefore increases the cost necessary to deter them from acquiring information.

The preceding discussion can help us answer the question that motivates this paper, specifically why government bonds are sold by auction and corporate bonds by PPS. To the extent that corporate bonds present credit risk but government bonds do not, the cost of acquiring information should be relatively low for government bonds and relatively high for corporate bonds. In line with the analysis above, the former should be sold by auction and the latter by PPS. What is more, corporate bonds should be sold at a discount. Both predictions appear to be borne out by the evidence: primary debt issues are sold by PPS, and they are underpriced on average. ${ }^{17}$

The fact that many emerging country government bonds are sold by PPS is in line with our analysis. Emerging country government bonds can present substantial credit risk. They are therefore more in the nature of corporate bonds than of government bonds.

We now consider the effect of the quality of information. ${ }^{18}$ The analysis above shows that an improvement in the quality of information leads to an increase in revenues with the auction, but to larger underpricing under PPS. Therefore, an improvement in the quality of information should favor auctions over PPS. Supporting this view are developments related to the internet. The internet can be argued to have made possible a dramatic improvement in the quality of the information available to market participants. It is credited with having occasioned "an enormous change in the opportunities for the use of auctions" (Pinker et al., 2001, p. 3), as evidenced for example by the profusion of B2B exchanges that use auctions or the introduction of the OpenIPO auction mechanism by W.R. Hambrecht+Co.

Finally, we consider the effect of the riskiness of the security. We know from the analyses of

\footnotetext{
${ }^{17}$ Smith (1999) reports the results of three studies, which find underpricing of primary debt issues to range from 5bp (Weinstein, 1978), through 50 bp (Sorensen, 1982), to 160bp (Smith, 1986). See also Ederington (1974) and Wasserfallen and Wydler (1988).

${ }^{18}$ The quality of information is of course not unrelated to its cost, as higher quality information can generally be obtained at higher cost. Nonetheless, they are not perfect substitutes.
} 
Sections 2 and 3 that an increase in riskiness decreases both expected seller proceeds in an auction and the price posted under PPS. It is therefore not clear how riskiness affects the choice between auctions and PPS. That greater riskiness favors auctions is suggested by the change from PPS to auctions for the sale of long-term government bonds that took place in the 1960s. Prior to that time, long-term government bonds had been sold by PPS (Goldstein, 1962). After a number of experiments with the use of auctions in the early part of the decade (Berney, 1964), the US and Canadian governments finally adopted auctions later in the decade. We note that the eventual adoption of auctions was more or less contemporaneous with the more volatile economic conditions of the late 1960s, and that such conditions must have led to an increase in the volatility of long-term government bonds.

\section{An Example}

In order to gain some insight into the properties of posted prices and auctions, let us consider an example. Suppose that the prior distribution of the value of the security is uniform on the interval $\left[V_{l}, V_{h}\right]$ and that a bidder observes a signal $X$ that is uniformly distributed around the true value $V$,

$$
X=V+\varepsilon, \quad \varepsilon \in[-\epsilon, \epsilon] .
$$

We wish to determine how the choice between the auction and the posted-price scheme depend on the riskiness of the security, $V_{h}-V_{l}$, the dispersion of the signal, $\epsilon$, and the information acquisition cost, $c$.

\subsection{The posted-price scheme}

Consider first the posted-price scheme. To compute the seller's expected payoff, we need to compute $E[V \mid X]$ and the distribution of $X$. Assume that $V_{l}+\epsilon<V_{h}-\epsilon$ (analogous computations can be performed for the other case as well). Then, since $X$ is the sum of two uniformly distributed random variables, it has a trapezoidal distribution with density function ${ }^{19}$

\footnotetext{
${ }^{19}$ This can be shown as follows. Recall that the density of $x$ is given by the convolution

$$
f_{X}(x)=\int_{-\infty}^{\infty} f_{V}(x-\varepsilon) f_{\varepsilon}(\varepsilon) d \varepsilon .
$$

Note that $f_{\varepsilon}(\varepsilon)=1 /(2 \epsilon)$ on $[-\epsilon, \epsilon]$ and 0 elsewhere. Hence,

$$
f_{X}(x)=\int_{-\epsilon}^{\epsilon} f_{V}(x-\varepsilon) \frac{1}{2 \epsilon} d \varepsilon .
$$

Now, $f_{V}(x-\varepsilon)=1 /\left(V_{h}-V_{l}\right)$ if $V_{l} \leq x-\varepsilon \leq V_{h}$ and 0 elsewhere. This condition, which can be written as $x-V_{h} \leq \varepsilon \leq x-V_{l}$, constrains the range of $\varepsilon$ over which $f_{V}$ is nonzero. Three cases can be distinguished. If
} 


$$
f_{X}(x)= \begin{cases}\frac{x+\epsilon-V_{l}}{2 \epsilon\left(V_{h}-V_{l}\right)}, & V_{l}-\epsilon \leq x \leq V_{l}+\epsilon \\ \frac{1}{V_{h}-V_{l}}, & V_{l}+\epsilon \leq x \leq V_{h}-\epsilon \\ \frac{V_{h}+\epsilon-x}{2 \epsilon\left(V_{h}-V_{l}\right)}, & V_{h}-\epsilon \leq x \leq V_{h}+\epsilon\end{cases}
$$

Conditional on observing the signal $X$, the expected value of the security is given by ${ }^{20}$

$$
E[V \mid X]= \begin{cases}\frac{V_{l}+X+\epsilon}{2}, & V_{l}-\epsilon \leq X \leq V_{l}+\epsilon \\ X, & V_{l}+\epsilon \leq X \leq V_{h}-\epsilon \\ \frac{V_{h}+X-\epsilon}{2}, & V_{h}-\epsilon \leq X \leq V_{h}+\epsilon\end{cases}
$$

To determine the magnitude of the discount required to deter information acquisition by buyers, we need to compute $E[\max [P-E(V \mid X), 0]]$. For $P \leq V_{l}+\epsilon$, we have

$$
E[\max [P-E[V \mid X], 0]]=\int_{V_{l}-\epsilon}^{2 P-V_{l}-\epsilon}\left(P-\frac{X+\epsilon+V_{l}}{2}\right) \frac{X+\epsilon-V_{l}}{2 \epsilon\left(V_{h}-V_{l}\right)} d X=\frac{\left(P-V_{l}\right)^{3}}{3 \epsilon\left(V_{h}-V_{l}\right)}
$$

$\overline{\left.x-V_{l} \leq \epsilon \text { (i.e., for } x \in\left[V_{l}-\epsilon, V_{l}+\epsilon\right]\right) \text {, one has }}$

$$
f_{X}(x)=\int_{-\epsilon}^{x-V_{l}} \frac{1}{V_{h}-V_{l}} \frac{1}{2 \epsilon} d \varepsilon=\frac{x+\epsilon-V_{l}}{2 \epsilon\left(V_{h}-V_{l}\right)} .
$$

If $x-V_{h} \geq-\epsilon$ (i.e., for $\left.x \in\left[V_{h}-\epsilon, V_{h}+\epsilon\right]\right)$, one has

$$
f_{X}(x)=\int_{x-V_{h}}^{\epsilon} \frac{1}{V_{h}-V_{l}} \frac{1}{2 \epsilon} d \varepsilon=\frac{V_{h}+\epsilon-x}{2 \epsilon\left(V_{h}-V_{l}\right)} .
$$

Finally, if $x-V_{l} \geq \epsilon$ and $-\epsilon \leq x-V_{h}$ (i.e., for $x \in\left[V_{l}+\epsilon, V_{h}-\epsilon\right]$ ), one has

$$
f_{X}(x)=\int_{-\epsilon}^{\epsilon} \frac{1}{V_{h}-V_{l}} \frac{1}{2 \epsilon} d \varepsilon=\frac{1}{V_{h}-V_{l}} .
$$

${ }^{20}$ Note that using Bayes' rule,

$$
E[V \mid X]=\frac{\int_{-\infty}^{\infty} V f_{X}(X \mid V) f_{V}(V) d V}{\int_{-\infty}^{\infty} f_{X}(X \mid V) f_{V}(V) d V}
$$

Using the fact that $f_{X}(x \mid V)=1 /(2 \epsilon)$ on $[V-\epsilon, V+\epsilon]$ and $f_{V}(V)=1 /\left(V_{h}-V_{l}\right)$ on $\left[V_{l}, V_{h}\right]$ and 0 elsewhere, one can again distinguish three cases. If $V_{l}+\epsilon \leq X \leq V_{h}-\epsilon$, one has

$$
E[V \mid X]=\frac{\int_{X-\epsilon}^{X+\epsilon} V \frac{1}{2 \epsilon} \frac{1}{V_{h}-V_{l}} d V}{\int_{X-\epsilon}^{X+\epsilon} \frac{1}{2 \epsilon} \frac{1}{V_{h}-V_{l}} d V}=\frac{\left.\frac{V^{2}}{2}\right|_{X-\epsilon} ^{X+\epsilon}}{\left.V\right|_{X-\epsilon} ^{X+\epsilon}}=X .
$$

If $X<V_{l}+\epsilon$, one has

$$
E[V \mid X]=\frac{\int_{V_{l}}^{X+\epsilon} V \frac{1}{2 \epsilon} \frac{1}{V_{h}-V_{l}} d V}{\int_{V_{l}}^{X+\epsilon} \frac{1}{2 \epsilon} \frac{1}{V_{h}-V_{l}} d V}=\frac{\left.\frac{V^{2}}{2}\right|_{V_{l}} ^{X+\epsilon}}{\left.V\right|_{V_{l}} ^{X+\epsilon}}=\frac{X+\epsilon+V_{l}}{2} .
$$

Finally, if $X>V_{h}-\epsilon$, one has

$$
E[V \mid X]=\frac{\int_{X-\epsilon}^{V_{h}} V \frac{1}{2 \epsilon} \frac{1}{V_{h}-V_{l}} d V}{\int_{X-\epsilon}^{V_{h}} \frac{1}{2 \epsilon} \frac{1}{V_{h}-V_{l}} d V}=\frac{\left.\frac{V^{2}}{2}\right|_{X-\epsilon} ^{V_{h}}}{\left.V\right|_{X-\epsilon} ^{V_{h}}}=\frac{V_{h}+X-\epsilon}{2} .
$$


and for $V_{l}+\epsilon \leq P \leq\left(V_{h}+V_{l}\right) / 2$,

$$
\begin{aligned}
E[\max [P-E[V \mid X], 0]] & =\int_{V_{l}-\epsilon}^{V_{l}+\epsilon}\left(P-\frac{X+\epsilon+V_{l}}{2}\right) \frac{X+\epsilon-V_{l}}{2 \epsilon\left(V_{h}-V_{l}\right)} d X+\int_{V_{l}+\epsilon}^{P} \frac{P-X}{V_{h}-V_{l}} d X \\
& =\frac{3\left(P-V_{l}\right)^{2}-\epsilon^{2}}{6\left(V_{h}-V_{l}\right)}
\end{aligned}
$$

Solving the no information acquisition condition $E[\max [P-E[V \mid X], 0]]=N c$ for $P$ then yields

$$
P= \begin{cases}V_{l}+\sqrt[3]{3 N c \epsilon\left(V_{h}-V_{l}\right)}, & P \leq V_{l}+\epsilon \\ V_{l}+\sqrt{2 N c\left(V_{h}-V_{l}\right)+\epsilon^{2} / 3}, & V_{l}+\epsilon \leq P \leq\left(V_{h}+V_{l}\right) / 2\end{cases}
$$

Note that when $c \leq \tilde{c} \equiv \epsilon^{2} /\left(3 N\left(V_{h}-V_{l}\right)\right), P \leq V_{l}+\epsilon$ and the first expression for $P$ applies, whereas when $c \geq \tilde{c}$, the second does. Summarizing, the posted-price schedule is given by

$$
P= \begin{cases}V_{l}+\sqrt[3]{3 N c \epsilon\left(V_{h}-V_{l}\right)}, & c \leq \frac{\epsilon^{2}}{3 N\left(V_{h}-V_{l}\right)} \\ V_{l}+\sqrt{2 N c\left(V_{h}-V_{l}\right)+\epsilon^{2} / 3}, & c \geq \frac{\epsilon^{2}}{3 N\left(V_{h}-V_{l}\right)}\end{cases}
$$

Let us consider its properties. Note first that for $c=0$, one has $P=V_{l}$, confirming the result that unless the posted price is set at the lower bound of the value distribution, buyers always choose to become informed if doing so is costless. Second, observe that $\partial P / \partial c>0$ for all $c$ : a higher information acquisition cost makes a smaller discount necessary to deter information acquisition. Third, $\partial P / \partial \epsilon>0$ : when the signal becomes less precise, a lower discount is required to prevent information acquisition. Finally, note that $\partial P / \partial\left(V_{h}-V_{l}\right)<0$ : a higher discount must be given to buyers in order to deter them from acquiring information about a more risky security. All these effects confirm the results of the general model of Section 3.

The information acquisition $\operatorname{cost} c_{h}$ such that information acquisition can be prevented without giving buyers a discount can be obtained as the solution to

$$
P=V_{l}+\sqrt{2 N c_{h}\left(V_{h}-V_{l}\right)+\frac{\epsilon^{2}}{3}}=\frac{V_{h}+V_{l}}{2}
$$

and is therefore given by

$$
c_{h}=\frac{V_{h}-V_{l}}{8 N}-\frac{\epsilon^{2}}{6 N\left(V_{h}-V_{l}\right)}
$$

Note that this amount increases both when the security becomes more risky $\left(V_{h}-V_{l}\right.$ rises) and when the precision of the signal increases ( $\epsilon$ falls).

Figure 1 pictures the posted price (upper panel) and the corresponding discount $\left(V_{h}+V_{l}\right) / 2-P$ (lower panel) as a function of the information acquisition cost $c$ for $N=10$ potential buyers, $V_{l}=0$, $V_{h}=1$ and two degrees of signal precision: $\epsilon=0.1$ (solid line) and $\epsilon=0.2$ (dashed line). Note first that for all values of the information acquisition cost, $P$ is higher for $\epsilon=0.2$ than for $\epsilon=0.1$. Also, observe that in both cases, underpricing diminishes rapidly as the information acquisition cost $c$ is 

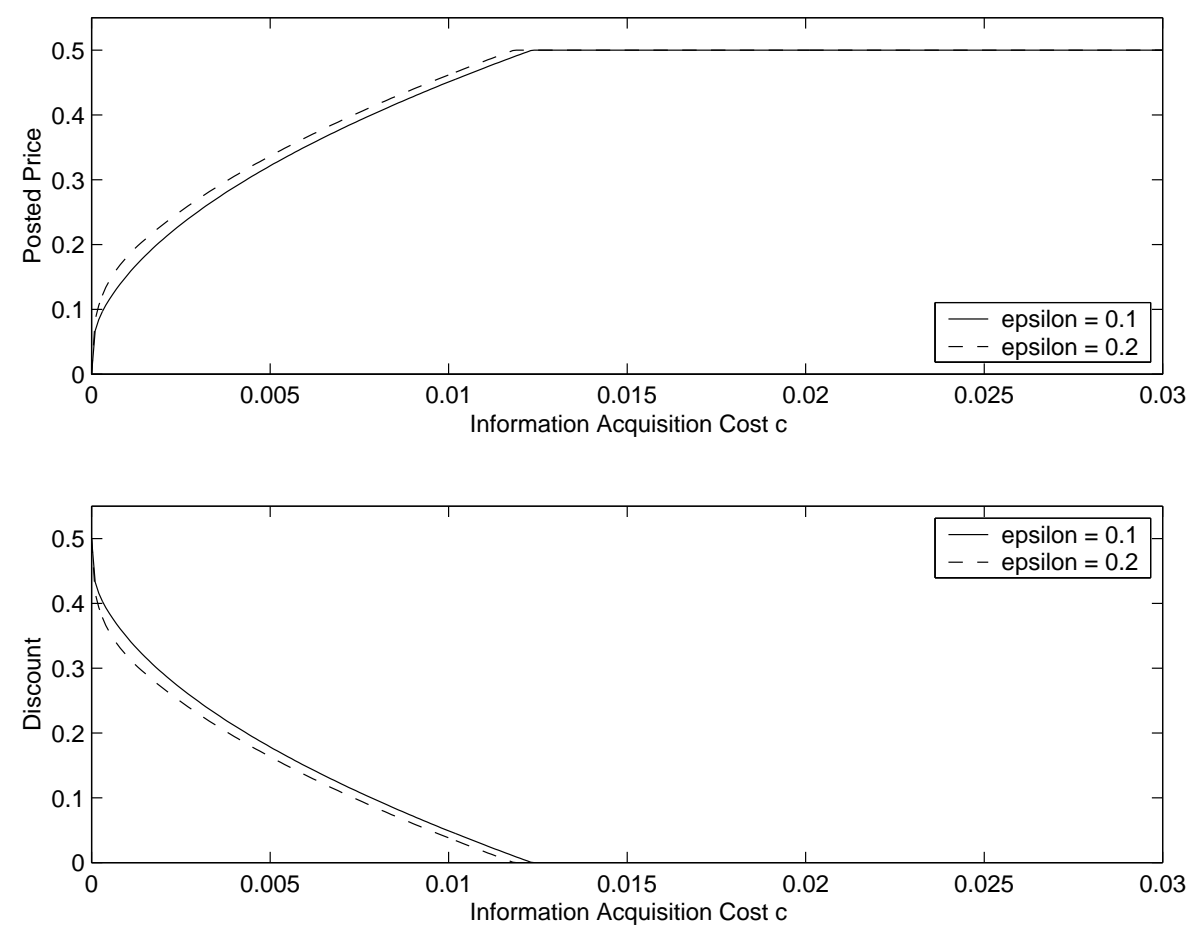

Figure 1: Posted price and discount as a function of the information acquisition cost $c$.

increased. For a value of $c$ exceeding $c_{h}$ (about 0.012 in both cases although, consistent with the general analysis, $c_{h}$ is lower when the signal dispersion is higher), no discount is required to deter information acquisition and the item can be sold at its unconditional expected value $\left(V_{h}+V_{l}\right) / 2$ using the posted-price scheme.

\subsection{The auction}

Kagel et al. (1995) show that in the setting considered here, the expected gross profit per bidder when $n$ bidders participate in the auction is given by

$$
\pi_{n}=2 \epsilon \frac{n-1}{n(n+1)}
$$

Hence, for an information acquisition $\operatorname{cost} c$, the number of bidders that choose to enter the auction is given by the lowest of the total number of potential buyers $N$ and the integer part of

$$
n^{*}=\frac{2 \epsilon-c+\sqrt{c^{2}-12 c \epsilon+4 \epsilon^{2}}}{2 c} .
$$

When $n^{*}>N$, all $N$ potential buyers acquire information, enter the auction and make a positive expected net profit of

$$
\pi_{N}-c=2 \epsilon \frac{N-1}{N(N+1)}-c
$$


When $n^{*} \leq N$, only some bidders enter the auction and — ignoring the integer constraint — make an expected profit of 0 .

As a result, underpricing in the auction is given by

$$
\begin{aligned}
N \pi_{N} & =2 \epsilon \frac{N-1}{N+1}, & n^{*} \geq N \\
n^{*} \pi_{n^{*}}=n^{*} c=\frac{2 \epsilon-c+\sqrt{c^{2}-12 c \epsilon+4 \epsilon^{2}}}{2}, & & n^{*}<N .
\end{aligned}
$$

Note first that underpricing tends to 0 as the signal dispersion $\epsilon$ tends to 0 and that underpricing increases with $\epsilon$,

$$
\begin{aligned}
\frac{\partial\left(N \pi_{N}\right)}{\partial \epsilon} & =2 \frac{N-1}{N+1}>0 \\
\frac{\partial\left(n^{*} c\right)}{\partial \epsilon} & =1+\frac{2 \epsilon-3 c}{\sqrt{c^{2}-12 c \epsilon+4 \epsilon^{2}}}>0 .
\end{aligned}
$$

Thus, the noisier the signal, the lower the seller's proceeds from the auction, in stark contrast to the posted-price scheme, where a noisier signal raises the seller's revenue.

Note also that for the range of $c$ over which all $N$ bidders enter the auction, underpricing is independent of $c$ and given by $N \pi_{N}=2 \epsilon(N-1) /(N+1)$. On the other hand, in this particular case, over the range of $c$ such that $n^{*}<N$, underpricing is decreasing in the information acquisition cost $c$, since

$$
\frac{\partial\left(n^{*} c\right)}{\partial c}=\frac{1}{2}\left(\frac{c-6 \epsilon}{\sqrt{c^{2}-12 c \epsilon+4 \epsilon^{2}}}-1\right)<0 .
$$

This is because the number of bidders $n^{*}$ participating in the auction reacts elastically to the information acquisition cost.

These effects are illustrated in Figure 2, which is based on the same parameter values as Figure 1. The upper panel depicts the number of bidders, the lower panel the expected revenue from the auction. When the signal is relatively precise $(\epsilon=0.1$, solid line), all $N=10$ potential buyers acquire information and participate in the auction when $c$ is less than 0.016. Over this range, underpricing is given by $2 \epsilon(N-1) /(N+1)=0.164$. When $c$ rises above 0.016 , the number of bidders falls below 10 sufficiently quickly that the expected revenue from the auction increases with c. On the other hand, when the signal is relatively noisy $(\epsilon=0.2$, dashed line), all 10 bidders participate in the auction over the range of values of $c$ considered and underpricing is constant at $2 \epsilon(N-1) /(N+1)=0.327$.

These results suggest that the seller may want to charge an entry fee in order to reduce the number of bidders participating in the auction and therefore aggregate underpricing. This is particularly true when $c$ is low and bidders' expected profit - net of the information acquisition cost — is positive. Paralleling the arguments in French and McCormick (1984), the best the seller can 

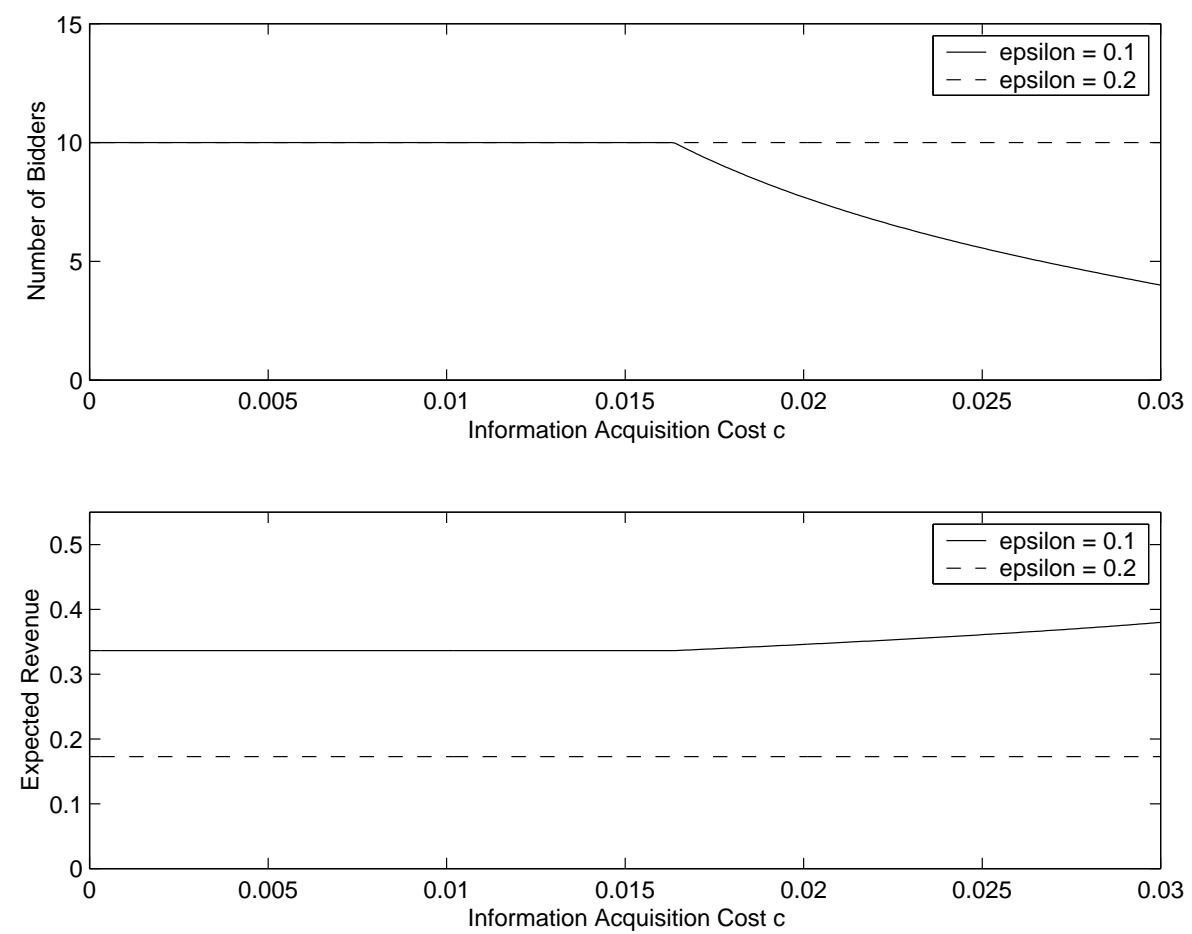

Figure 2: Number of bidders and expected revenue from the auction as a function of the information acquisition $\operatorname{cost} c$.

do is to constrain the number of entrants to 2 bidders. He can do this by setting an entry fee $k$ such that

$$
\pi_{n}=2 \epsilon \frac{n-1}{n(n+1)}=c+k
$$

is satisfied for $n=2$. Solving, the optimal entry fee is given by

$$
k=\frac{\epsilon}{3}-c .
$$

Note that the optimal entry fee is increasing in signal dispersion, reflecting the fact that bidders' expected gross profit and therefore their incentive to enter the auction is increasing in signal dispersion.

Although the entry fee allows the seller to constrain the number of bidders participating in the auction, it is not able to deter them from acquiring information. Interestingly, since the optimal entry fee eliminates the impact of signal dispersion on bidders' incentives to enter the auction, the seller's expected revenue with entry fees becomes independent of signal dispersion and equals $E[V]-2 c=\left(V_{h}+V_{l}\right) / 2-2 c$. 

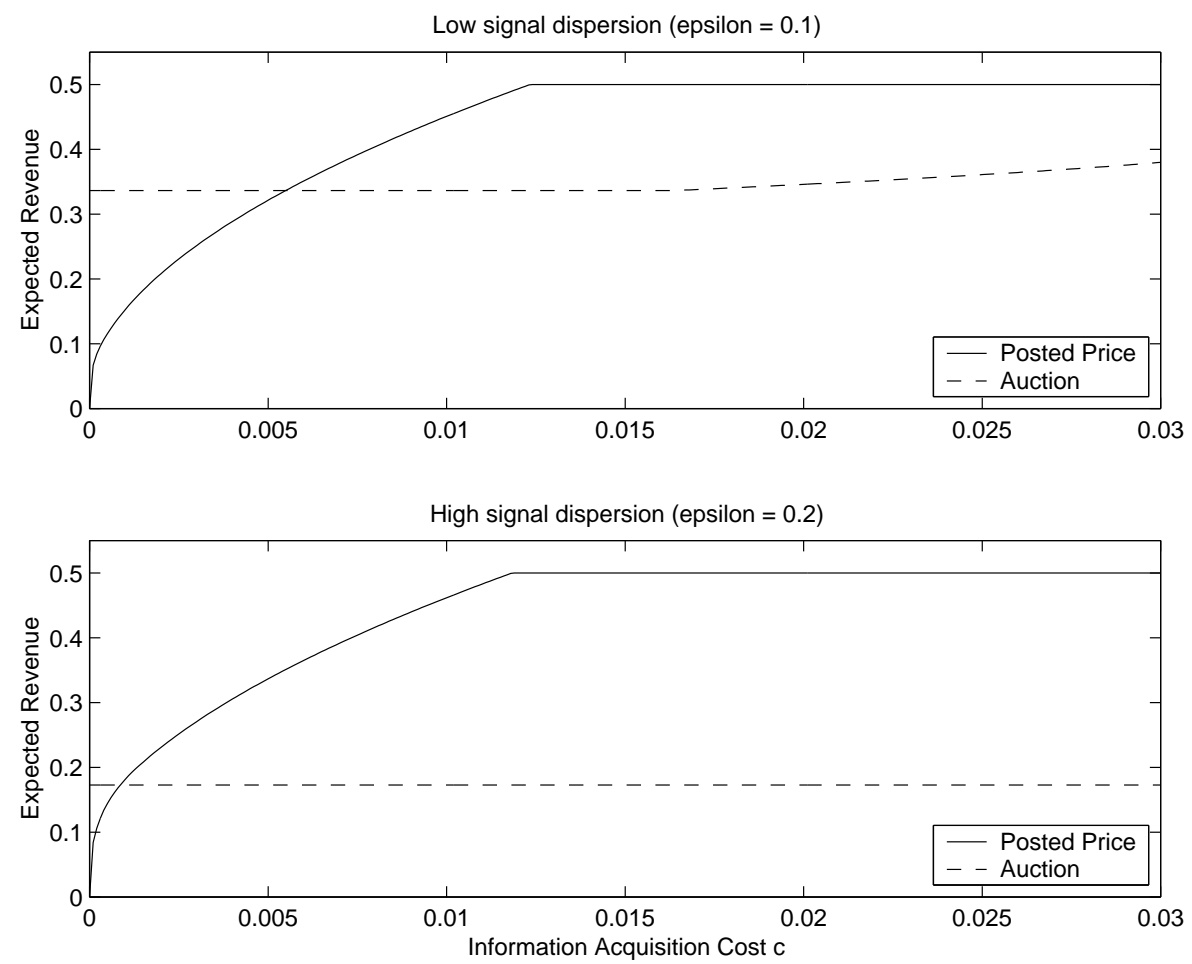

Figure 3: Expected revenue from the auction and the posted price scheme as a function of the information acquisition cost $c$.

\subsection{The posted-price scheme and the auction compared}

Figure 3 compares the revenue from the posted-price scheme and the auction for the situation considered above when there are no entry fees. The upper panel considers the case of low signal dispersion $(\epsilon=0.1)$, the lower panel that of high signal dispersion $(\epsilon=0.2)$. Note that in both cases, the auction is preferred when the information acquisition cost is low, and the posted-price scheme when it is high. In the case where signal dispersion is relatively low (upper panel), bidders' expected profits and the number of bidders that enter the auction are not very large, and the auction is preferred to the posted price scheme for values of $c$ between 0 and 0.005 . In contrast, when signal dispersion is relatively high (lower panel), bidders' expected profits and the number of bidders entering the auction - and therefore underpricing in the auction - are larger, and the posted price scheme is preferred for virtually all values of the information acquisition cost $c$. Note also that in the particular case considered here, since the riskiness of the security $V_{h}-V_{l}$ has no effect on the profit from the auction and reduces the optimal posted price, it favors the auction.

Figure 4 performs the same comparison when the seller uses entry fees to reduce the number of participating bidders. Recall that in this case, the auction's expected revenue is $E[V]-2 c$ and does not depend on the signal's dispersion. The seller's revenue from using the auction again exceeds that from the posted price when the information acquisition cost is low. For values of $c$ 


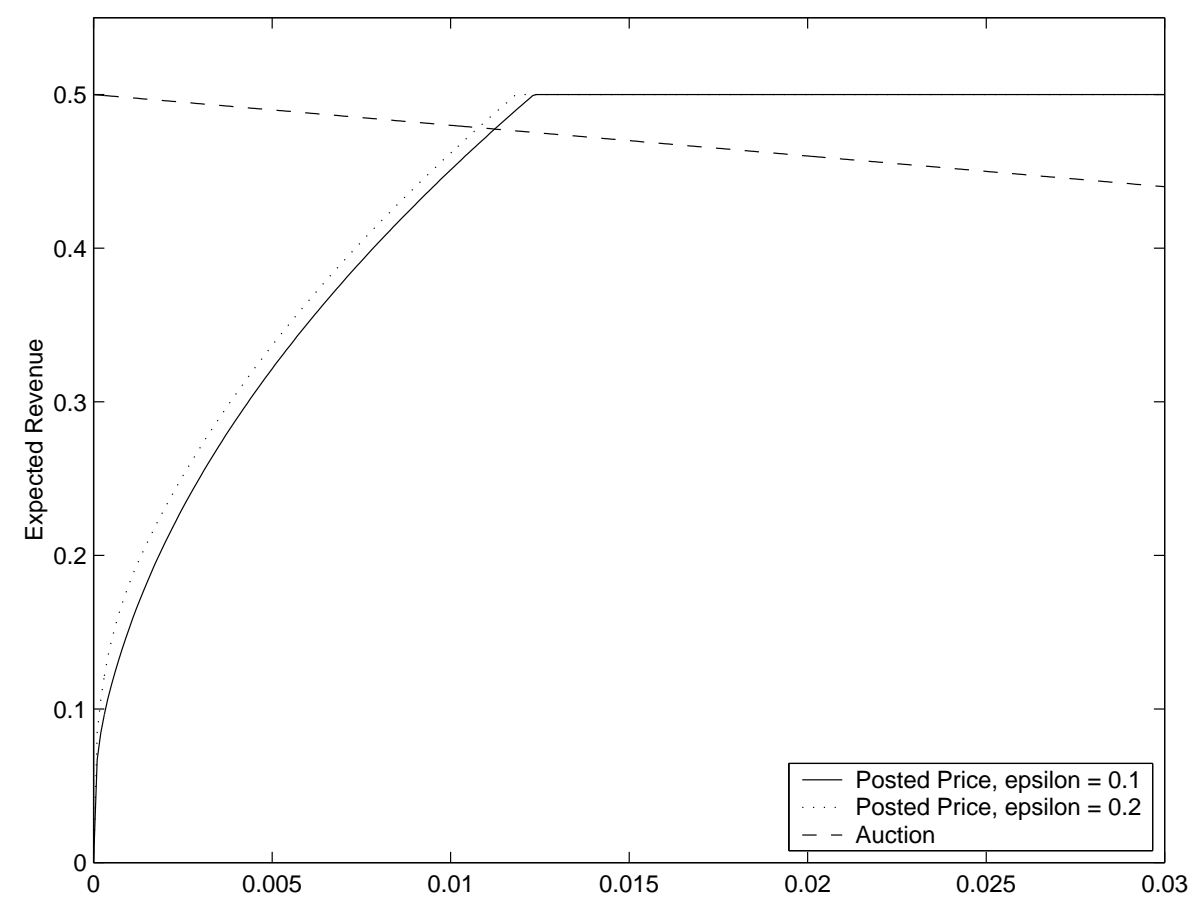

Figure 4: Expected revenue from the auction and the posted price scheme as a function of the information acquisition cost $c$ when entry fees are used.

exceeding about 0.011, however, the posted price is preferred. Furthermore, consistent with our earlier analysis, the range of values of $c$ over which the posted price is preferred to the auction is larger, the greater the dispersion of the signal. Thus, just as in the case without fees, a lower signal quality favors the posted price over the auction, and a higher riskiness of the security has the opposite effect.

\section{Implications for initial public offerings}

We now briefly turn our attention from bonds to shares. An implication of the preceding analysis is that shares should be sold by PPS. This is because the cost of acquiring information about stocks should be higher than it is for bonds, and the quality of the information obtained lower. ${ }^{21}$ Indeed, in her study of IPOs in 44 countries, Sherman (2001, Table 1) finds that auctions are used in only 5 countries. $^{22}$ PPS, either alone in the form of a fixed-price offering, or preceded by "pre-play communication" in the form of book-building (Spatt and Srivastava, 1991), clearly dominates. As

\footnotetext{
${ }^{21}$ The greater difficulty of valuing stocks as compared to bonds forms the basis of the Pecking Order Theory of capital structure (Myers, 1984, Myers and Majluf, 1984).

${ }^{22}$ This figure can possibly be extended to 7 countries, as Sherman (2001) is uncertain about the use of auctions in 2 countries.
} 
noted in the introduction, Sherman (2001) has preceded us in ascribing the benefits of PPS to the better control it affords the seller over the amount of information acquired by investors. However, as Sherman (2001, footnote 5) has recognized, entry fees into an auction for shares can achieve much of the control over the acquisition of information that she deems necessary. What entry fees into an auction cannot achieve - but PPS can - is the prevention of information acquisition that constitutes the focus of our paper.

An objection to the use of PPS in IPOs is that underpricing appears to be greater with bookbuilding than with auctions (Derrien and Womack, 2002; Kaneko and Pettway, 2001). We note, however, that a reasoning such as ours makes no predictions as to how average underpricing relates to the choice of selling scheme. Instead, it suggests that the selling scheme chosen will be that which minimizes underpricing for given values of the cost of acquiring information, the quality of the information acquired, and the riskiness of the security. It therefore cautions against the adoption of a selling scheme used in one setting in another setting.

To illustrate this last point, consider the case of IPOs in Israel. ${ }^{23}$ Kandel, Sarig, and Wohl (1999) report that in Israel, where the use of auctions for IPOs is prevalent, average underpricing is $4.5 \%$, about a third of the figure for the United States. Does this suggest that auctions should be used in other IPO markets, such as the United States?

Not if we consider the following. The average elasticity of demand estimated by Kandel et al. (1999) is 37.1, far above the figures reported for the United States. For example, in her analysis of 31 Dutch auction share repurchases, Bagwell (1992) estimates an average elasticity of $0.68 .^{24}$ As noted by Kandel et al. (1999), the very high elasticity they estimate indicates that bidders have very similar assessments of the value of the securities sold in the IPO. Combined with the large average number of orders (4,077, Table 1, Kandel et al., 1999), this suggests that the cost of information acquisition, $c$, is very low in Israel, and the quality of the information acquired very high. We are unable to explain why that should be the case. However, we can conclude from the result that seller proceeds in a common value auction are increasing in the homogeneity of bidders' information that an attempt to use auctions in a country such as the United States where the low elasticity of demand suggests that bidders have heterogeneous information would likely result in markedly higher underpricing than is observed in Israel. ${ }^{25}$

\footnotetext{
${ }^{23}$ A somewhat analogous point is made by Kutsuna and Smith (2001) for Japan.

${ }^{24}$ See also Loderer, Cooney, and Van Drunen (1991), Hodrick (1999), and Kaul, Mehrotra, and Mørck (2000).

${ }^{25}$ The low elasticity in the United States can partly be ascribed to tax rather than information considerations. However, the estimate by Loderer et al. (1991) of an average elasticity of 11 attributable exclusively to tax considerations suggests that taxes alone are unlikely to account for the entire difference between Bagwell's (1992) estimates and those of Kandel et al. (1999).
} 


\section{Conclusion}

We believe a general lesson can be drawn from our analysis. It is that i) the strength with which the price and allocation prescribed by a selling scheme react to investors' bids and ii) investors' incentives to acquire information are forms of strategic complements. ${ }^{26}$ The allocation reacts very weakly and the price not at all to investors' bids under PPS, but much more strongly in an auction. ${ }^{27}$ This makes investors' incentives to acquire information much greater in auctions than under PPS, to the point that only those investors who have acquired information will enter a bid in an auction. In contrast, the price posted by the seller under PPS can be set in such way as to deny investors any incentive to acquire information.

Our comparison of auctions and PPS can be viewed as extending Persico's (2000) comparison of first- and second-price auctions. As discussed by Chari and Weber (1992) and shown formally by Persico (2000), the incentives to acquire information are lower in second-price auctions than in their first-price counterparts. In a first-price auction, it is valuable to bid close to one's opponents to minimize the price paid upon winning. Information helps in making such bids. No such concern arises in a second-price auction, because the price paid by the winner does not depend on the bid he has entered. Our analysis demonstrates that PPS gives investors even lower incentives to acquire information than do second-price auctions. Indeed, PPS can be used fully to deter them from acquiring information.

Our analysis is also related to the work of Parlour and Rajan (2002). They analyze an auction with a rationing scheme in which the winning bidder is chosen randomly among the $K$ highest bidders and the price paid by the winning bidder is set at the $K+1$ th highest bid. They show that rationing with $K=N-1$ is optimal when bidders have low quality information. This effect arises because rationing mitigates the winner's curse. Their result recalls our result that PPS dominates auctions when the information investors may acquire is of low quality, because PPS can be viewed as rationing among all $N$ bidders. In such case, the sale price must of course be set by the seller, for buyers would otherwise bid only the lowest value for the item being sold.

Throughout, we have assumed that the decision to acquire information was an 'all-or-nothing' decision: information either was acquired in its entirety, or it was not acquired at all. This is not likely to be the case in practice. Instead, some information may be acquired at such a low cost that the seller will not wish to preclude its acquisition. Other information may be sufficiently costly to acquire that the seller will be able to preclude its acquisition at the cost of a relatively small discount.

\footnotetext{
${ }^{26}$ See Bulow, Geanakoplos, and Klemperer (1985) for an analysis of strategic substitutes and complements.

${ }^{27}$ Under PPS, the allocation depends only on investors' decision whether to place a bid, but not on the amount bid.
} 
Does the presence of these two sorts of information invalidate our analysis? We believe the answer is in the negative. We conjecture that the need for PPS intended to preclude the acquisition of the second sort of information will remain, but that PPS will be combined with screening or preplay communication intended to induce investors to reveal truthfully the first sort of information.

We believe IPOs are a case in point. Investors in an IPO may acquire information about the general state of demand for the security simply by virtue of being on the 'buy-side' of the market. They are likely to need to spend substantial resources to form a very detailed assessment of the value of the shares of the company taken public. We view book-building - that is pre-play communication followed by PPS (Spatt and Srivastava, 1991) — as combining the acquisition of the former sort of information with the preclusion of the latter. We leave these issues for further research. 


\section{References}

Arnold, M.A. and S.A. Lippman, 1998, Selecting a selling institution: auctions versus sequential search, Economic Inquiry 33, 1-23.

Bagwell, L.S., 1992, Dutch auction repurchases: an analysis of shareholder heterogeneity, Journal of Finance 47, 71-105.

Berney, R.E., 1964, The auction of long-term government securities, Journal of Finance 19, 470-482.

Bikhchandani, S. and C.-f. Huang, 1993, The economics of the Treasury securities markets, Journal of Economic Perspectives 7, 117-134.

Blackwell, D., 1953, Equivalent comparisons of experiments, Annals of Mathematical Statistics $24,265-273$.

Blackwell, D. and M.A. Girshick, 1954, Theory of Games and Statistical Decisions, John Wiley, New York.

Bulow, J.I. and P.D. Klemperer, 1996, Auctions versus negotiations, American Economic Review $86,180-194$.

Bulow, J.I., J.D. Geanakoplos, and P.D. Klemperer, 1985, Multimarket oligopoly: strategic substitutes and complements, Journal of Political Economy 93, 488-511.

Chari, V.V. and R.J. Weber, 1992, How the U.S. treasury should auction its debt, Federal Reserve Bank of Minneapolis Quarterly Review 16, 3-12.

Chemmanur, T.J. and H. Liu, 2001, How should a firm go public? A dynamic model of the choice between fixed-price offerings and auctions in IPOs and privatizations, working paper, Boston College.

Derrien, F. and K.L. Womack, 2002, Auctions vs. book-building and the control of underpricing in hot IPO markets, forthcoming, Review of Financial Studies.

Ederington, L.H., 1974, The yield spread on new issues of corporate bonds, Journal of Finance 29, 1531-1543.

French, K.R. and R.E. McCormick, 1984, Sealed bids, sunk costs, and the process of competition, Journal of Business 57, 417-441.

Goldstein, H.N., 1962, Should the Treasury auction long-term securities? Journal of Finance 17, 444-464. 
Grinblatt M. and S. Titman, 1998, Financial Markets and Corporate Strategy, Irwin/McGrawHill, Boston, MA.

Harstad, R.M., 1990, Alternative common-value auction procedures: revenue comparisons with free entry, Journal of Political Economy 98, 421-429.

Harstad, R.M., 1991, Asymmetric bidding in second-price, common-value auctions, Economics Letters 35, 249-252.

Hodrick, L.S., 1999, Does stock price elasticity affect corporate financial decisions? Journal of Financial Economics 52, 225-256.

Kagel, J.H., D. Levin, and R.M. Harstad, 1995, Comparative static effects of number of bidders and public information on behavior in second-price common value auctions, International Journal of Game Theory 24, 293-319.

Kandel, S., O. Sarig, and A. Wohl, 1999, The demand for stocks: an analysis of IPO auctions, Review of Financial Studies 12, 227-247.

Kaneko, T. and R. Pettway, 2001, Auctions versus book-building underwriting of Japanese IPOs: OTC, Mothers, and NASDAQ-Japan issues, working paper, University of Missouri.

Kaul, A., V. Mehrotra, and R. Mørck, 2000, Demand curves for stocks do slope down: New evidence from an index weights adjustment, Journal of Finance 55, 893-912.

Kutsuna, K. and R.L. Smith, 2001, Issue cost and method of IPO underpricing: Japan's change from auction method pricing to book-building, working paper, Claremont Graduate University.

Levin, D. and R.M. Harstad, 1986, Symmetric bidding in second price common value auctions, Economics Letters 20, 315-319.

Levin, D. and J.L. Smith, 1994, Equilibrium in auctions with entry, American Economic Review 84, 585-599.

Loderer, C., J.W. Cooney, and L.D. van Drunen, 1991, The price elasticity of the demand for common stock, Journal of Finance 46, 621-651.

Madhavan, A., 1992, Trading mechanisms in securities markets, Journal of Finance 47, 607-641.

Milgrom, P.R., 1981, Rational expectations, information acquisition, and competitive bidding, Econometrica 49, 921-943.

Milgrom, P.R. and R.J. Weber, 1982a, The value of information in a sealed-bid auction, Journal of Mathematical Economics 10, 105-114. 
Milgrom, P.R. and R.J. Weber, 1982b, A theory of auctions and competitive bidding, Econometrica 50, 1089-1122.

Myers, S.C., 1984, The capital structure puzzle, Journal of Finance 39, 575-592.

Myers, S.C. and N. Majluf, 1984, Corporate financing and investment decisions when firms have information investors do not have, Journal of Financial Economics 13, 187-221.

Parlour, C.A. and U. Rajan, 2002, Rationing and common values, working paper, Carnegie Mellon University.

Persico, N., 2000, Information acquisition in auctions, Econometrica 68, 135-148.

Pinker, E.J., A. Seidmann, and Y. Vakrat, 2001, The design of online auctions: business issues and current research, working paper, University of Rochester.

Rock, K., 1986, Why new issues are underpriced, Journal of Financial Economics 15, 187-212.

Sherman, A.E., 2001, Global trends in IPO methods: book-building vs. auctions, working paper, University of Notre-Dame.

Smith, C.W. Jr., 1986, Investment banking and the capital acquisition process, Journal of Financial Economics 15, 3-29.

Smith, C.W. Jr., 1999, Raising capital: theory and evidence, in D.H. Chew Jr. (ed.), The New Corporate Finance (2nd ed.), Irwin/McGraw-Hill, Boston, MA.

Sorensen, E.H., 1982, On the seasoning process of new bonds: some are more seasoned than others, Journal of Financial and Quantitative Analysis 17, 195-208.

Spatt, C. and S. Srivastava, 1991, Preplay communication, participation restrictions, and efficiency in initial public offerings, Review of Financial Studies 4, 709-726.

Wang, R., 1993, Auctions versus posted-price selling, American Economic Review 83, 838-851.

Wang, R., 1998, Auctions versus posted-price selling: the case of correlated private valuations, Canadian Journal of Economics 31, 395-410.

Wasserfallen, W. and D. Wydler, 1988, Underpricing of newly-issued bonds: evidence from the Swiss capital market, Journal of Finance 43, 1177-1191.

Weinstein, M.I., 1978, The seasoning process of new corporate bond issues, Journal of Finance $33,1343-54$.

Wilson, R., 1977, A bidding model of perfect competition, Review of Economic Studies 44, 511-518. 